\begin{tabular}{|c|l|}
\hline Title & The z value dependence of photoluminescence in Eu^[2+]-doped $\beta$-SiA ION (Si_[6-z]A IzOzN_[8_z]) with $1 \quad$ z $\quad 4$ \\
\hline Author(s) & Zhu, X.W.; Masubuchi, Y.; Motohashi, T.; Kikkawa, S. \\
\hline Citation & $\begin{array}{l}\text { Journal of A Illoys and Compounds, 489(1), 157-161 } \\
\text { https://doi.org/10.1016/.jallcom.2009.09.042 }\end{array}$ \\
\hline Issue Date & 2010-01-07 \\
\hline Doc URL & http://hdl.handle.net/2115/42556 \\
\hline Type & article(author version) \\
\hline File Information & JAC489-1_157-161.pdf \\
\hline
\end{tabular}

Instructions for use 


\title{
The $\mathrm{z}$ value dependence of photoluminescence in $\mathrm{Eu}^{2+}$-doped $\beta$-SiAlON $\left(\mathrm{Si}_{6-\mathrm{z}} \mathrm{Al}_{\mathrm{z}} \mathrm{O}_{\mathrm{z}} \mathrm{N}_{8-\mathrm{z}}\right)$ with $1 \leq \mathrm{z} \leq 4$
}

X. W. Zhu, Y. Masubuchi, T. Motohashi, and S. Kikkawa

Graduate School of Engineering, Hokkaido University, N13W8, Kita-ku, Sapporo, 060-8628, Japan

\begin{abstract}
$\mathrm{Eu}^{2+}$-doped $\beta$-SiAlON $\left(\mathrm{Si}_{6-\mathrm{z}} \mathrm{Al}_{\mathrm{z}} \mathrm{O}_{\mathrm{z}} \mathrm{N}_{8-\mathrm{z}}\right)$ phosphors with $1 \leq \mathrm{z} \leq 4$ were synthesized by gas pressure sintering. The emission spectra exhibit two broad bands with maxima at about $415 \mathrm{~nm}$ (violet) and $540 \mathrm{~nm}$ (green) under ultraviolet excitation. The green emission is dominant at $\mathrm{z} \leq 2$, while the violet emission becomes dominant at $\mathrm{z}>2$. The combination of two emission bands in a compound could lead to a white emission in $\mathrm{Eu}^{2+}$-doped $\beta$-SiAlON with $2<\mathrm{z} \leq 3$.
\end{abstract}

Keywords: SiAlON; Luminescent materials; Powder processing; X-ray diffraction (XRD); Optical properties

\section{Introduction}

$\mathrm{Si}_{3} \mathrm{~N}_{4}$-based ceramics are the leading engineering ceramics for high-temperature structural application of excellent thermal and mechanical properties [1]. $\mathrm{Si}_{3} \mathrm{~N}_{4}$ occurs in two major crystalline phases: $\alpha$ and $\beta$ [2]. Both phases have a hexagonal structure consisting of corner-sharing $\mathrm{SiN}_{4}$ tetrahedra but different stacking sequences; it is $\mathrm{ABCD}$ in $\alpha$ and $\mathrm{AB}$ in $\beta$. They have their respective solid solutions, known as $\alpha$ - and $\beta$-SiAlON, described by the general formulae $\mathrm{M}_{\mathrm{m} / \mathrm{v}} \mathrm{Si}_{12-(\mathrm{m}+\mathrm{n})} \mathrm{Al}_{\mathrm{m}+\mathrm{n}} \mathrm{O}_{\mathrm{n}} \mathrm{N}_{16-\mathrm{n}}\left(v\right.$ is the valence of the metal $\mathrm{M}$ ion) and $\mathrm{Si}_{6-\mathrm{z}} \mathrm{Al}_{\mathrm{z}} \mathrm{O}_{\mathrm{z}} \mathrm{N}_{8-\mathrm{z}}(0<\mathrm{z} \leq 4.2)$ [3]. Both $\alpha$ - and $\beta$-SiAlONs have been used as host lattices for rare-earth (RE) ions to generate efficient luminescence [4-8]. For example, $\mathrm{Eu}^{2+}$-doped $\mathrm{Ca}-\alpha$ - and $\beta$-SiAlONs give yellow and green 
emissions, respectively. The RE-doped SiAlON phosphors have expected to be used in white light-emitting diodes (LEDs), owing to the high thermal and chemical stabilities [9].

The $\beta$-SiAlON has received less attention as a host material for phosphors in comparison with the $\alpha$-SiAlON. This may be due to the fact that the $\alpha$-SiAlON has interstitial sites for RE ions, whereas the $\beta$-SiAlON has no apparent crystallographic sites for RE ions. Despite this, in the $\beta$-SiAlON structure there are continuous channels parallel to the $c$-axis [10]. In 1985, RE-doped $\beta$-SiAlON phosphors were first developed by Popma [7] to be used in luminescent screens excited by ultraviolet (UV), electron and X-ray radiation, with a focus on the case of $z=3$. They showed various color emissions, depending on the type of $\mathrm{RE}$, e.g., $\mathrm{Eu}^{2+}$ for violet-blue emission at $410 \sim$ $440 \mathrm{~nm}$ and $\mathrm{Sm}^{2+}$ for red emission at $685 \sim 740 \mathrm{~nm}$. Recently, Hirosaki et al. [8] reported a green emission at $535 \mathrm{~nm}$ under the UV or blue light excitation in $\beta-\mathrm{SiAlON}: \mathrm{Eu}^{2+}$ with $\mathrm{z}=0.14$. Xie et al. [11] reported the red shift in emission wavelength from 528 to $550 \mathrm{~nm}$ with increasing $\mathrm{z}$ value in $\beta$-SiAlON:Eu ${ }^{2+}$ phosphors at $\mathrm{z} \leq 2$. They also showed that the critical concentration depends on the $\mathrm{z}$ value and the $\beta$-SiAlON: $\mathrm{Eu}^{2+}$ phosphors have a small thermal quenching. Ryu et al. [12] further studied the concentration and thermal quenching of $\beta$-SiAlON:Eu ${ }^{2+}$ phosphors with $z=0.23$. The green emission was also reported in the $\beta$-SiAlON:Eu ${ }^{2+}$ with $\mathrm{z} \leq 2$ produced by combustion synthesis [13]. These studies indicate that the RE ions like $\mathrm{Eu}^{2+}$ can indeed be incorporated into the $\beta$-SiAlON structure, being assumed to exist in continuous channels $[8,9,14]$. Very recently, this assumption has been experimentally demonstrated by direct observation using scanning transmission electron microscopy (STEM) [15].

Previous studies indicate that the $\beta-\mathrm{SiAlON}: \mathrm{Eu}^{2+}$ emits the green light for $\mathrm{z} \leq 2$ but the violet-blue lights for $z=3$. The color change appears to be consistent with the decrease in its N/O ratio, because RE-doped oxynitride materials usually show shorter emission wavelengths with decreasing N/O ratio, due to the reduced nephelauxetic effect and crystal-field splitting [4,9]. However, it is unclear whether the $\beta-\mathrm{SiAlON}: \mathrm{Eu}^{2+}$ shows a continuous shift in emission band from green to violet lights as well as the mixed emission bands at particular wavelengths with varying $\mathrm{z}$ 
values within the whole range of $0-4.2$. Tuning $\mathrm{z}$ values in $\beta-\mathrm{SiAlON}: \mathrm{Eu}^{2+}$ may have a possibility to lead to the phosphors generating emissions ranging from violet to green colors. This is of interest to expand applications of $\beta$-SiAlON as luminescent materials. Unfortunately, the study dealing with the effect of $\mathrm{z}$ value on the photoluminescence of $\beta-\mathrm{SiAlON}: \mathrm{Eu}^{2+}$ within the whole $\mathrm{z}$ range is not found yet. The objective of this paper is to investigate the effect of $\mathrm{z}$ value on the photoluminescence of $\beta$-SiAlON: $\mathrm{Eu}^{2+}$ within the range of $1 \leq \mathrm{z} \leq 4$.

\section{Experimental}

The starting materials used for producing $\mathrm{Eu}^{2+}$-doped $\beta$-SiAlON $\left(\mathrm{Si}_{6-\mathrm{z}} \mathrm{Al}_{\mathrm{z}} \mathrm{O}_{\mathrm{z}} \mathrm{N}_{8-\mathrm{z}}\right)$ were $\alpha-\mathrm{Si}_{3} \mathrm{~N}_{4}$ (SN-E10, Ube Industries, Ltd., Japan), $\mathrm{Al}_{2} \mathrm{O}_{3}$ (99.99\%, Kojundo Chemical Laboratory, Japan), AlN (Grade H, Tokuyama Corp., Japan) and $\mathrm{Eu}_{2} \mathrm{O}_{3}$ (99.9\%, Wako Pure Chemical Industries Ltd., Japan). The $\mathrm{z}$ value was varied from 1 to 4 at a fixed Eu concentration of $0.5 \mathrm{~mol} \%$ with respect to $\beta$-SiAlON. The raw powders were homogeneously mixed with absolute ethanol in a plastic bottle with $\mathrm{Si}_{3} \mathrm{~N}_{4}$ balls by ball milling. After vacuum drying, the powder mixtures were packed into $\mathrm{BN}$ crucibles, and then fired in a gas pressure sintering furnace at $1900{ }^{\circ} \mathrm{C}$ for $3 \mathrm{~h}$ under a nitrogen pressure of $0.5 \mathrm{MPa}$. After firing, the power was shut off and the samples were cooled down in the furnace. Phase identification of the synthesized powders were conducted by powder X-ray diffraction (XRD) (Ultima IV, Rigaku, Tokyo, Japan) with monochromatized $\mathrm{CuK}_{\alpha}$ radiation of $40 \mathrm{kV} / 40 \mathrm{~mA}$ at a scanning speed of $2 \%$ min in the $2 \theta$ range of $10-120^{\circ}$. Morphologies of the products were observed by a scanning electron microscope (SEM) (JSM-6390LV, JEOL, Tokyo, Japan). Photoluminescence spectra of the synthesized powders were measured at room temperature by a spectrofluorometer (FP-6500, JASCO, Tokyo, Japan) with a $150 \mathrm{~W}$ xenon lamp as an excitation source.

\section{Results and discussion}

Figure 1 (a) shows that at $\mathrm{z}=1$, the sample consists of a $\beta$-SiAlON phase; at $\mathrm{z}=2$, the sample 
consists of a major $\beta$-SiAlON phase and a trace amount of impurity phases AlN and 15R AlN-polytypoid $\left(\mathrm{SiAl}_{4} \mathrm{O}_{2} \mathrm{~N}_{4}\right)$; at $\mathrm{z}=3$ and 4 , the samples consists of a major $\beta$-SiAlON phase and an impurity 15R. The relative amount of the impurity $15 \mathrm{R}$ increases with $\mathrm{z}$ value increasing from 2 to 4. Xie et al. [11] have reported the formation of Eu-doped $\beta$-SiAlON with $\mathrm{z} \leq 2$ by gas pressure sintering. They obtained the pure $\beta$-SiAlON phase only at lower $z$ values of $z<1$, above which AlN-polytypoid impurities (e.g., 12H, 21R and 27R) were present regardless of the Eu concentration. They assume that this phenomenon is attributed to the decreased solubility of $\mathrm{Eu}^{2+}$ in $\beta$-SiAlON with increasing z values. In the work of Zhou et al. [13], no secondary AlN-polytypoid phases were observed in the $4 \mathrm{~mol} \%$ Eu-doped $\beta$-SiAlON with $\mathrm{z} \leq 2$ by combustion synthesis method. This implies that the formation of $\beta-\mathrm{SiAlON}$ is not associated with the solubility of $\mathrm{Eu}^{2+}$ but its composition, which is affected by the starting powders and processing conditions. According to the phase diagram of the $\mathrm{Si}_{3} \mathrm{~N}_{4}-\mathrm{SiO}_{2}-\mathrm{Al}_{2} \mathrm{O}_{3}$-AlN system, $\beta$-SiAlON is compatible with $15 \mathrm{R}$ in the region of $\mathrm{Si} / \mathrm{Al}<3$ or $\mathrm{z}>1.5$ [16]. As a result, in case of $\mathrm{z} \geq 2$, the formation of the impurity $15 \mathrm{R}$ is reasonable when a small change occurs in the composition during firing. Figure 1 (a) also shows that the diffraction peaks of $\beta$-SiAlON shift to smaller diffraction angles $2 \theta$ with increasing $\mathrm{z}$ value. This is due to the substitution of Al-O $(0.175 \mathrm{~nm})$ for $\mathrm{Si}-\mathrm{N}(0.174 \mathrm{~nm})$, thereby resulting in the lattice expansion. Figure 1 (b) reveals that the lattice parameters show a linear increase with increasing z value, which is in good agreement with the report of Ekström et al [17]. This confirms that the resultant $\beta$-SiAlON powders have the nominal compostions $\mathrm{Si}_{6-\mathrm{z}} \mathrm{Al}_{\mathrm{z}} \mathrm{O}_{\mathrm{z}} \mathrm{N}_{8-\mathrm{z}}$ as designed.

Figure 2 shows the SEM photographs of the synthesized $\mathrm{Eu}^{2+}$-doped $\beta$-SiAlON powders with various $\mathrm{z}$ values. In call cases, the grains show predominantly near-equiaxed shapes, whereas the grain size shows a significant increase with increasing $\mathrm{z}$ value from 1 to 4 . For example, the grain size is $\sim 0.5 \mu \mathrm{m}$ for $\mathrm{z}=1$ and $\sim 2 \mu \mathrm{m}$ for $\mathrm{z}=3$. This result is consistent with previous studies that the $\mathrm{Eu}^{2+}$-doped $\beta$-SiAlON grains show a rodlike shape at $\mathrm{z}<1$ but a near-equiaxed shape at $\mathrm{z} \geq 1$ $[11,13]$. The changed shape and size of the $\beta$-SiAlON grains with increasing $\mathrm{z}$ value are generally thought to be associated with the increased amount of the transient liquid phase that promotes the 
dissolution-precipitation process for the grain growth.

As shown in Fig. 3 (a), the shape of excitation spectrum depends on the emission condition. The excitation spectra under emission at $412 \mathrm{~nm}$ have two broad bands centered at about 277 and $321 \mathrm{~nm}$. As reported previously $[8,11,13]$, the excitation spectra under emission at $540 \mathrm{~nm}$ have several broad bands centered at about 301, 336, 411 and $450 \mathrm{~nm}$. The broad band excitation is attributed to the $4 \mathrm{f}^{7} \rightarrow 4 \mathrm{f}^{6} 5 \mathrm{~d}$ transition of $\mathrm{Eu}^{2+}$. Meanwhile, at $\mathrm{z} \leq 2$, the excitation intensity under emission at $412 \mathrm{~nm}$ is weaker than that under emission at $540 \mathrm{~nm}$, whereas at $\mathrm{z}>2$, the former becomes substantially stronger than the latter.

The emission spectrum under excitation at $301 \mathrm{~nm}$ depends strongly on the $\mathrm{z}$ value, as shown in Fig. 3 (b). At $z=1,2$, and 3, the emission spectra exhibit two broad bands centered at about 415 and $540 \mathrm{~nm}$. These two broad emissions should be attributed to the $4 \mathrm{f}^{6} 5 \mathrm{~d} \rightarrow 4 \mathrm{f}^{7}$ transition of $\mathrm{Eu}^{2+}$. No line emission peaks of $\mathrm{Eu}^{3+}(590-615 \mathrm{~nm})$ are observed. This suggests that $\mathrm{Eu}^{3+}$ ions in the $\mathrm{Eu}_{2} \mathrm{O}_{3}$ raw material is reduced to $\mathrm{Eu}^{2+}$ ions in the $\beta$-SiAlON products in a reducing nitrogen atmosphere, similar to the previous reports $[8,11-14]$. The reduction may be due to the reaction $6 \mathrm{Eu}^{3+}+2 \mathrm{~N}^{3-} \Rightarrow 6 \mathrm{Eu}^{2+}+\mathrm{N}_{2}$, as proposed by de Graaf [18]. At $\mathrm{z}=4$, the emission spectrum exhibits a single broad band with a maximum at $409 \mathrm{~nm}$. This means that the violet emission intensity increases but the green emsision intensity decreases with increasing $\mathrm{z}$ value. The rapid change in the emission occurs between $z=2$ and 3 . In addition, the violet emission at $z=4$ is signficantly stronger than the green emission at $\mathrm{z}=1$. The violet emission was reported at $\mathrm{z}=3$ by Pompa [7]. The emisson peak at about $420 \mathrm{~nm}$ was also observed at $\mathrm{z}=2$ by Zhou et al [13]. In their work, no AlN-polytypoid phases were present. Although the impuirty phase $15 \mathrm{R}$ is present at $\mathrm{z}=2,3$ and 4 in the present work, the $\mathrm{Eu}^{2+}$-doped $15 \mathrm{R}$ has been found to exhibit an emission band with a maximum at about $450 \mathrm{~nm}$, which is less affeced by the synthesizing conditions [19]. The violet emission should result from the $\mathrm{Eu}^{2+}$-doped $\beta$-SiAlON, and this emisson becomes dominant over the green one when $\mathrm{z}>2$.

Morevoer, the two emission peaks obsvered against $\mathrm{z}$ value are summarized in Table 1. As 
reported previously, the green emission wavelength shows a slight increase (i.e., red shift) with increasing $\mathrm{z}$ value from 1 to 2 . Xie et al. [11] suggested that the red shift of green emission is attributed to the Stokes shift as a result of the decreased rigidity of the $\beta$-SiAlON lattice with increasing $\mathrm{z}$ value. However, with $\mathrm{z}$ value increasing to 3 , the green emission shows a slight decrease in wavelength and eventually disappears at $z=4$. In contast, the violet emission band shifts gradually toward shorter wavelenths (i.e., blue shift) with increasing z value. The blue shift may be related to the expansion of the unit cell and the decreased covalence of the chemical bonds with increasing $\mathrm{z}$ value.

The emission spectra showing two broad bands in a comound is possible in $\mathrm{Eu}^{2+}$-doped nitride and oxide materials. Höppe et al.[20] observed two emission bands with maxima at 610 and $630 \mathrm{~nm}$ in $\mathrm{Eu}^{2+}$-doped $\mathrm{Ba}_{2} \mathrm{Si}_{5} \mathrm{~N}_{8}$ under excitation with intense laser light at $1.047 \mu \mathrm{m}$. They are attributed to two crystallographic $\mathrm{Eu}^{2+}$ sites in the channels along [100]. Denis et al. [21] reported that the $\mathrm{Eu}^{2+}$-doped $(\mathrm{Ba}, \mathrm{Sr})_{13-\mathrm{x}} \mathrm{Al}_{22-2 \mathrm{x}} \mathrm{Si}_{10+2 \mathrm{x}} \mathrm{O}_{66}$ exhibits two broad emission bands with maxima at 438 and $534 \mathrm{~nm}$, resulting in the white fluorescence and phosphorescence. This luminescence is attributed to the three crystallographic $\mathrm{Ba}$ sites labeled $\mathrm{Ba} 1, \mathrm{Ba} 2$ and $\mathrm{Ba} 3$ in $\mathrm{Ba}_{13-\mathrm{x}} \mathrm{Al}_{22-2 \mathrm{x}} \mathrm{Si}_{10+2 \mathrm{x}} \mathrm{O}_{66}$. The occupation of $\mathrm{Eu}^{2+}$ at the $\mathrm{Ba} 1$ and $\mathrm{Ba} 2$ sites gives the blue-violet emission (438 nm), while the occupation of $\mathrm{Eu}^{2+}$ at the $\mathrm{Ba} 3$ site gives the green emission (534 nm). Kikkawa et al. [22] reported three emission bands with maxima at 400, 475 and $520 \mathrm{~nm}$ in the $\mathrm{Eu}^{2+}$-doped $\mathrm{AlON}$ with an impurity of $\mathrm{EuAl}_{12} \mathrm{O}_{19}$ under excitation at $254 \mathrm{~nm}$. The authors attributed the possible reason for the three emission bands to the different coordination environments of $\mathrm{Eu}^{2+}$ with $\mathrm{O}^{2-} / \mathrm{N}^{3-}$ in the magnetoplumbite structure.

There is no available crystallographic site for $\mathrm{Eu}^{2+}$ ion in $\beta$-SiAlON, so it is difficult to correlate the luminescence with the chemical environment of $\mathrm{Eu}^{2+}$ in $\beta$-SiAlON. It has continuous channels to accommodate for $\mathrm{Eu}^{2+}$ ions, as confirmed by STEM without any detailed crystallographic information [15]. By modeling analysis, Li et al. [14] showed that the $\mathrm{Eu}^{2+}$ ion occupies the $2 \mathrm{~b}$ site $(0,0,0)$ in the channels and coordinates to six $(\mathrm{N} / \mathrm{O})$ atoms. They also suggested 
the general formula $\mathrm{Eu}_{\mathrm{x}} \mathrm{Si}_{6-\mathrm{z}} \mathrm{Al}_{\mathrm{z}-\mathrm{x}} \mathrm{O}_{\mathrm{z}+\mathrm{x}} \mathrm{N}_{8-\mathrm{z}-\mathrm{x}}$ for the $\mathrm{Eu}^{2+}$-doped $\beta$-SiAlON. Generally, the luminescence of RE-doped (oxy)nitride depends on the coordination of the RE ion with $\mathrm{N}$ and $\mathrm{O}$ ions. When the activator ion (e.g., $\mathrm{Eu}^{2+}$ or $\mathrm{Ce}^{3+}$ ) coordinates to more $\mathrm{N}$ than $\mathrm{O}$ ions, the nephelauxetic effect is enhanced and the crystal-field splitting of the $5 \mathrm{~d}$ band is enlarged, thereby resulting in the longer excitation and longer emission wavelengths. The N/O ratio decreases in $\mathrm{Eu}^{2+}$-doped $\beta$-SiAlON with increasing $\mathrm{z}$ value, so the excitation and emission wavelength are expected to decrease. This appears to agree with the fact: the green emission at $\mathrm{z}<1$ and the violet emission at $\mathrm{z}>3$. The present results suggest that there are two different kinds of $\mathrm{N} / \mathrm{O}$ coordinations around $\mathrm{Eu}^{2+}$ ions in $\beta$-SiAlON; one with oxygen-rich gives the violet emission $(\sim 415$ $\mathrm{nm})$, and the other with nitrogen-rich gives the green emission $(\sim 540 \mathrm{~nm})$. The green emission is dominant at lower $\mathrm{z}$ values, while violet emission is dominant at higher $\mathrm{z}$ values.

Figure 4 shows the CIE (Commission International del' Eclairage) 1931 chromaticity coordinates of the synthesized $\mathrm{Eu}^{2+}$-doped $\beta$-SiAlON phosphors. The chromaticity index $(\mathrm{x}, \mathrm{y})$ shifts from $(0.34,0.55),(0.33,0.48),(0.23,0.23)$ to $(0.19,0.08)$ with an increasing $\mathrm{z}$ value from 1 to 4 , corresponding to the colors of green, greenish-yellow, pale violet, and to violet. It is of interest to see that the chromaticity index can be located at near the white color region by changing $\mathrm{z}$ value between 3 and 4 . This means that the $\mathrm{Eu}^{2+}$-doped $\beta$-SiAlON alone may give a white emission under UV excitation. Particularly, we have observed a near-white emission from the sample with $\mathrm{z}=3$ in a handy UV lamp under $365 \mathrm{~nm}$ excitation. The white emission should be attributed to the coexistence of the violet and green emssions. This suggests the possibility to obtain the white emssion from the single phase of $\mathrm{Eu}^{2+}$-doped $\beta$-SiAlON by carefully adjusting its $\mathrm{z}$ value as well as Eu content. The $\mathrm{Eu}^{2+}$-doped $\beta$-SiAlON itself may act as a potential single-phased white-emitting phosphor for UV LEDs.

\section{Conclusions}

The emission spectra of $\mathrm{Eu}^{2+}$-doped $\beta$-SiAlON phosphors with $1 \leq \mathrm{z} \leq 4$ were found to exhibit 
two broad emission bands with maxima at about $415 \mathrm{~nm}$ (violet) and $540 \mathrm{~nm}$ (green) under UV excitation, resulting in a white emission. The violet emission becomes dominant with increasing $\mathrm{z}$ value, while the green emission eventually disappears with $\mathrm{z}$ value increasing to 4 . The results suggest that there are probably two different kinds of $\mathrm{N} / \mathrm{O}$ coordinations around $\mathrm{Eu}^{2+}$ ions in $\beta$-SiAlON; one with oxygen-rich and the other with nitrogen-rich. This study implies that the $\mathrm{Eu}^{2+}-$ doped $\beta$-SiAlON itself may act as a potential single-phased white-emitting phosphor for UV LEDs.

\section{Acknowledgements}

This work was supported in part by a Grant-in-Aid for specially promoted research from the JSPS of Japan under Grant No. 20900101, and X.W.Z appreciates the fellowship from the Hokkaido University Global COE Program "Catalysis as the Basis for Innovation in Materials Science”.

\section{References}

[1] F. L. Riley, J. Am. Ceram. Soc. 83 (2000) 245.

[2] D. Hardie, K. H. Jack, Nature, 180 (1957) 332.

[3] T. Ekström, M. Nygren, J. Am. Ceram. Soc. 75 (1992) 259.

[4] J. W. H. van Krevel, J. W. T. Van Rutten, H. Mandal, H. T. Hintzen, R. Metselaar, J. Solid State Chem. 165 (2002) 19.

[5] R. J. Xie, M. Mitomo, K. Uheda, F. F. Xu, Y. Akimune, J. Am. Ceram. Soc. 85 (2002) 1229.

[6] T. Suehiro, N. Hirosaki, R. J. Xie, M. Mitomo, Chem. Mater. 17 (2005) 308.

[7] T. J. Popma, European patent, EP 0155047 A1, 1985.

[8] N. Hirosaki, R. J. Xie, K. Kimoto, T. Sekiguchi, Y. Yamamoto, T. Suehiro, M. Mitomo, Appl. Phys. Lett. 86 (2005) 211905.

[9] R. J. Xie, N. Kirosaki, Sci. Technol. Adv. Mater. 8 (2007) 588.

[10] R. Grün, Acta Crystallogr. B 35 (1979) 800.

[11] R. J. Xie, N. Hirosaki, H. L. Xie, Y. Q. Li, M. Mitomo, J. Electrochem. Soc. 154 (2007) J314. 
[12] J. H. Ryu, Y. G. Park, H. S. Won, H. Suzuki, S. H. Kim, C. Yoon, J. Ceram. Soc. Jpn. 116 (2008) 389 .

[13] Y. Zhou, Y. Yoshizawa, K. Hirao, Z. Lenčéš, P. Šajgalík, J. Am. Ceram. Soc. 91 (2008) 3082.

[14] Y. Q. Li, N. Hirosaki, R. J. Xie, T. Takeda, M. Mitomo, J. Solid State Chem. 181 (2008) 3200.

[15] K. Kimoto, R. J. Xie, Y. Matsui, K. Ishizuka, N. Hirosaki, Appl. Phys. Lett. 94 (2009) 041908.

[16] L. J. Gauckler, H. L. Lukas, G. Petzow, J. Am. Ceram. Soc. 58 (1975) 346.

[17] T. Ekström, P. O. Käll, M. Nygren, P. O. Olsson, J. Mater. Sci. 24 (1989) 1853.

[18] D. de Graaf, H. T. Hintzen, S. Hampshire, G. de With, J. Eur. Ceram. Soc. 23 (2003) 1093.

[19] X. W. Zhu, Y. Masubuchi, T. Motohashi, S. Kikkawa, T. Takeda, J. Am. Ceram. Soc., submitted.

[20] H. A. Höppe, H. Lutz, P. Morys, W.Schnick, A.Seilmeier, J. Phys. Chem. Solids, 61 (2000) 2001.

[21] G. Denis, P. Deniard, E. Gautron, F. Clabau, A. Garcia, S. Jobic, Inorg. Mater. 47 (2008) 4226.

[22] S. Kikkawa, N. Hatta, T. Takeda, J. Am. Ceram. Soc. 91 (2008) 924. 


\section{Captions of tables}

Table 1. Effect of $z$ value on the emission peaks observed under excitation at $301 \mathrm{~nm}$.

\section{Captions of figures}

Fig. 1. (a) XRD patterns and (b) lattice parameters of the synthesized $\mathrm{Eu}^{2+}$-doped $\beta$-SiAlON powders with various $\mathrm{z}$ values.

Fig. 2. SEM photographs of the synthesized $\mathrm{Eu}^{2+}$-doped $\beta$-SiAlON powders with $\mathrm{z}$ values of (a) 1 , (b) 2 , (c) 3 and (d) 4 .

Fig. 3. (a) Excitation and (b) emission spectra of the synthesized $\mathrm{Eu}^{2+}$-doped $\beta$-SiAlON powders with various $\mathrm{z}$ values.

Fig. 4. CIE 1931 chromaticity coordinates of the synthesized $\mathrm{Eu}^{2+}$-doped $\beta$-SiAlON powders with various z values under excitation at $301 \mathrm{~nm}$. CIE coordinates calculated using the software GoCIE obtained from http://www.geocities.com/krjustin/gocie.html. 
Table 1. Effect of $\mathrm{z}$ value on the emission peaks observed under excitation at $301 \mathrm{~nm}$.

\begin{tabular}{ccc}
\hline z value & Violet emission peak $(\mathrm{nm})$ & Green emission peak $(\mathrm{nm})$ \\
\hline 1 & 418 & 541 \\
2 & 415 & 543 \\
3 & 412 & 540 \\
4 & 409 & ND \\
\hline
\end{tabular}



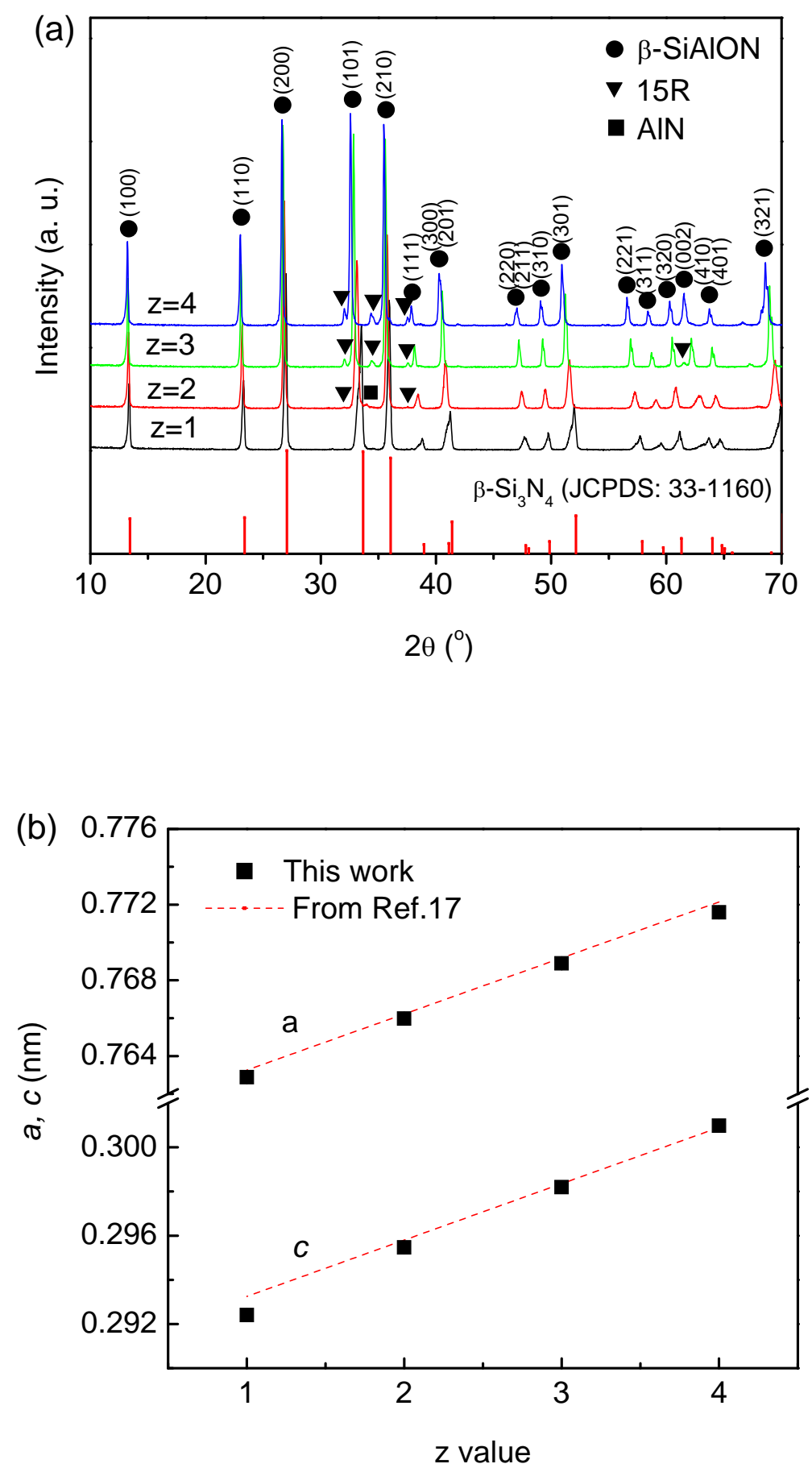

Fig. 1. (a) XRD patterns and (b) lattice parameters of the synthesized $\mathrm{Eu}^{2+}$-doped $\beta$-SiAlON powders with various $\mathrm{z}$ values. 

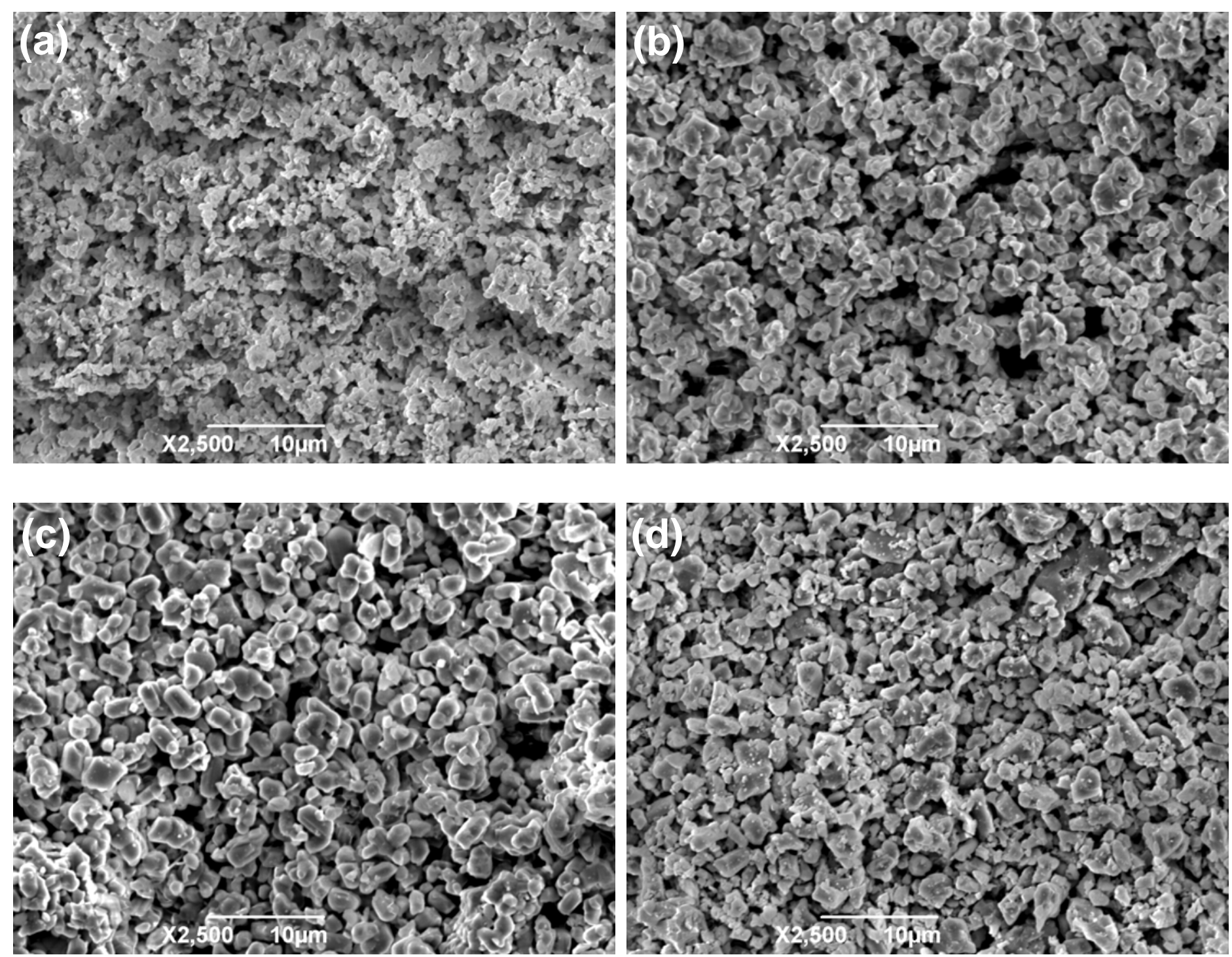

Fig. 2. SEM photographs of the synthesized $\mathrm{Eu}^{2+}$-doped $\beta$-SiAlON powders with $\mathrm{z}$ values of (a) 1, (b) 2, (c) 3 and (d) 4 . 

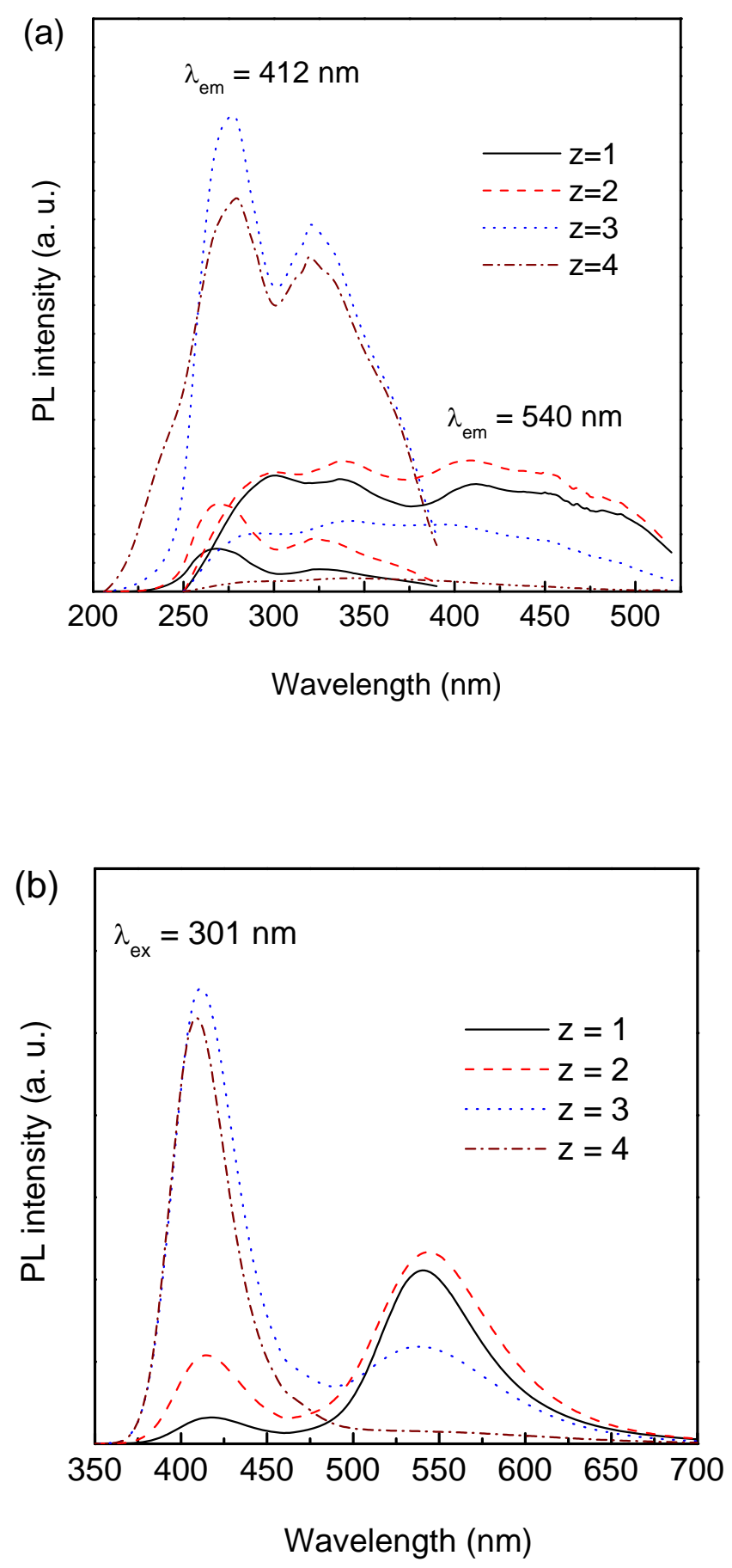

Fig. 3. (a) Excitation and (b) emission spectra of the synthesized $\mathrm{Eu}^{2+}$-doped $\beta$-SiAlON powders with various $\mathrm{z}$ values. 


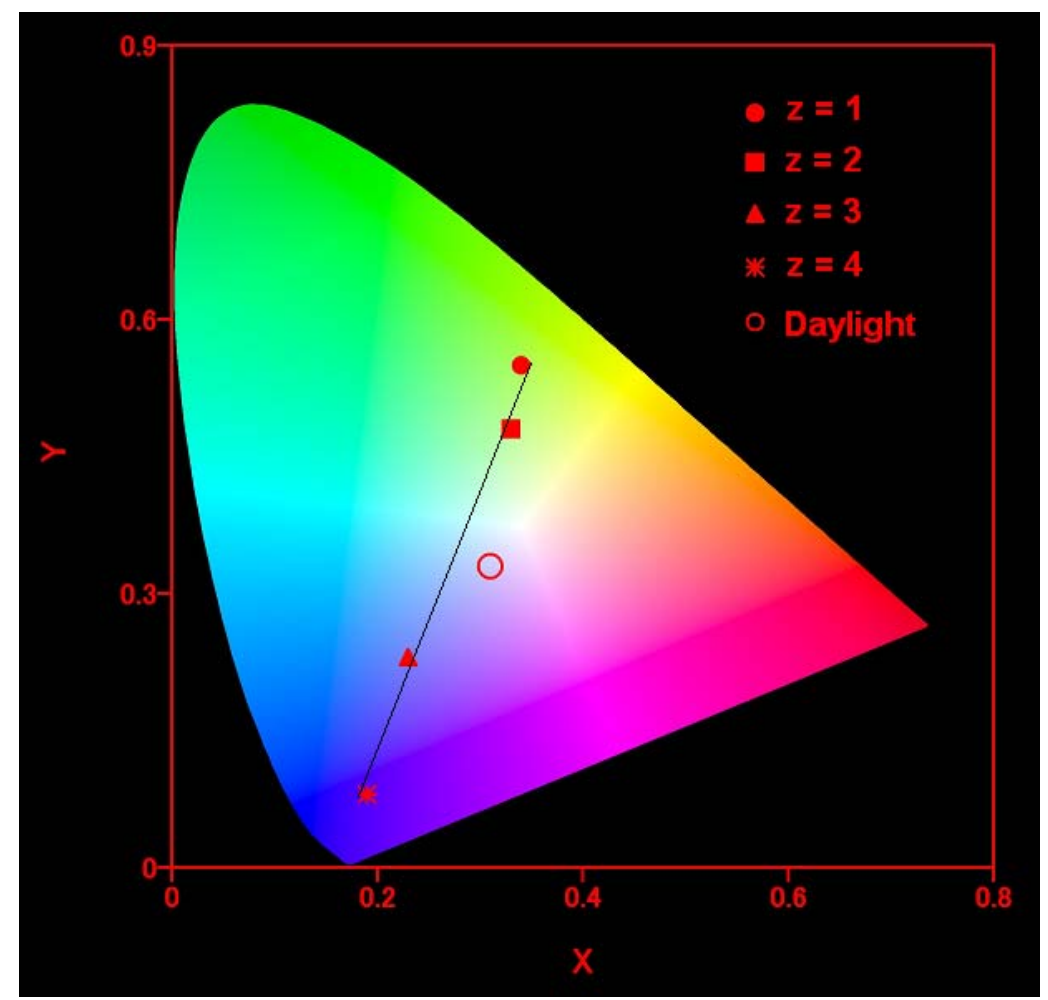

Fig. 4. CIE 1931 chromaticity coordinates of the synthesized $\mathrm{Eu}^{2+}$-doped $\beta$-SiAlON powders with various z values under excitation at $301 \mathrm{~nm}$. CIE coordinates calculated using the software GoCIE obtained from http://www.geocities.com/krjustin/gocie.html. 